\title{
Research on Customer Rescue Model of TPL Enterprise under the "New Retail"
}

\author{
Yong Wang*, Pei-lin Zhang \\ School of Transportation, \\ Wuhan University of Technology \\ Wuhan, Hubei, China \\ *Corresponding author
}

\author{
Cornel Mihai Nicolescu \\ Department of Production Engineering \\ KTH Royal Institute of Technology \\ Stockholm, Sweden
}

\author{
Ting Zhang, Qingying Zhang \\ School of Logistics \\ Wuhan Technology and Business University \\ Wuhan, Hubei, China
}

\begin{abstract}
New retail" is the application of new Internet technologies and new thinking. It is an improvement and innovation on traditional retail methods and selling products or services to consumers. "New Retail" is a new way in contact with consumers, so that consumers can buy the goods they need in a short time. The core of "new retail" is to enhance the user experience. This paper starts with the theoretical knowledge of customer relationship management. Under the background of "new retail", this paper analyzes the current situation of RK logistics and RK logistics implementation of customer relationship management to find out the problem. At the same time, this paper takes the Fs project as an example, using the Rescue Model to compare the customer's residual value and rescue costs to determine whether the customer is worth saving. Finally, suggestions for improving the customer relationship of RK Logistics are proposed. The paper implements the "customer-centric" philosophy in the new retail context, improves the customer relationship management system, strengthens the maintenance of existing cus tomers and calculates the rescue cost.
\end{abstract}

Keywords-New Retail; RK Logistics; Customer Relationship Management; Customer Rescue Model

\section{INTRODUCTION}

With the development of information technology and the acceleration of globalization, the world has stepped into an era of universal application and integration of market economy. For enterprises, the region is no longer a limit, so the competition between enterprises is increasingly fierce, and the customer's demand for enterprises and products is also higher and higher. "New retail" refers to the retail industry will be combined with online and offline, the use of modern logistics services and other cloud computing, big data and other technologies, constitute a new retail model". But in the "Internet plus" era, the new retail model will lead the future business trends. In addition, the mainstream electricity supplier giants combined with its electricity supplier business operations present situation and trends, have defined the new retail. "New retail" core is to enhance the user experience, and

Sponsors: CSC Project (201708420201); MOE Project of Humanities and Social Sciences (14YJCZH154); WTBU Academic Team (XSTD2015004). promote online, offline and logistics and other cross-border integration. At the same time, the "new retail" basis and premise is to reconstruct the supply chain and upgrade the logistics program. Thus, logistics plays a crucial role in "new retail".

The choice of customers is geared to the global market and is approaching diversification and personalization. The pressure on these enterprises has gradually increased, and the market has changed from a seller's market to a buyer's market. New retail background, in order to long-term development, enterprises should focus on customer needs above, in-depth understanding of it, and then try to quickly and meet the individual needs of customers. Thus, customer relationship management came into being, which is a new type of management mechanism. It can develop large customers at low cost and effectively prevent customer churn. If enterprises want to carry out customer relationship management so as to enhance their competitive edge and occupy their market share, they must analyze their customers and fully understand their customers. [1]

According to the latest data of Armstrong \& Associates show that as of the end of 2016, in the global logistics industry competitiveness ranking (Logistics Performance Index) in European countries, the performance of the most prominent, the German LPI (logistics industry boom index) score of 4.23, ranking first in the world. The region with the strongest competitiveness in the region is Singapore (4.19 in the world, fifth in the world), followed by Hongkong in China, while China ranks only twenty-seventh in the world. [2]

\section{NEW FEATURES OF LOGISTICS DEVELOPMENT UNDER NEW RETAIL BACKGROUND}

"New retail" and "New logistics" is a brand new retail business services in the form of two inseparable parts, there is no "new logistics", there will be no "new retail", and the two are common development. At present, in the "new retail" and "new logistics" in the exploration and de velopment, has shown some trends. 
First, sales and logistics channels sink. In the first tier cities in the market, because each electricity supplier logistics distribution service network is more comprehensive, and now the logistics system can fully meet the basic needs of consumers. Therefore, the consumer experience is not very different. But if we sink into the two or three tier cities and even the vast rural markets, the sales system and logistics service system are lagging behind the potential consumer demand. In these markets, we need some new business models, namely "new retail"+ "new logistics"model.

Second, the integration of traditional sales and logistics channels, convenience stores become a new round of competition focus. A few years ago, the focus of competition is electricity supplier giants $\mathrm{B} 2 \mathrm{C}$ business. In recent years, the electricity supplier giants in retail B2B field (traditional wholesale field) moves frequently: Ali launched a retail business, JD promote millions of convenience store program. These electricity supplier giants to enter, making the original field of this secret and complex logistics service system, either directly with these large logistics platform competition, otherwise, is to integrate into these large logistics platform. [3]

Third, all sales channels, logistics system integration, coordinated development. Through the "Online + offline + logistics" depth of integration, to achieve comprehensive integration of goods and logistics channels. Offline retailers develop online channels, online retailers to develop offline channels, offline retailers and online retailers to cooperate to achieve complementary channels and win-win situation. The current mainstream retailers have been part of the domestic business enterprise is carried out under the line and complementary channels.

Fourth, big data and other cutting-edge information technology become "new logistics" crucial ability, including: small format sinking, retail to the community and township extension; brand control terminal; unity and differentiation symbiosis.

Fifth, "new retail" and "new logistics" development gives more space on the development of intelligent logistics equipment. New retail era, new requirements for logistics systems, such as order fulfillment systems for high speed and reliability. [4]

\section{RK LOGISTICS AND CUSTOMER RELATIONSHIP MANAGEMENT}

\section{A. RK Logistics}

RK Supply Chain Logistics Co. Ltd. (hereinafter referred to as "RK logistics") was established in 1985 through the ISO9001 international quality certification, is a comprehensive logistics enterprise with a set of cold chain, general transport, chemical industry as the core business, to provide customers with the national highway transportation, warehousing and distribution, integrated supply chain service. RK logistics is the Ministry of transport to suspend transportation pilot enterprises, China's food cold chain logistics, China's pharmaceutical cold chain logistics national standards demonstration enterprises. [5]
At present, nearly 50 branches have been set up throughout the country, covering more than 1500 cities, including Shanghai, Beijing, Nanjing, Suzhou and Wuxi. RK logistics has its own transport vehicles up to more than 1300 vehicles, including more than 450 cold chain vehicles, more than 230 dangerous goods transport vehicles, are equipped with GPS vehicle monitoring system, cooperative vehicle resources of more than 9200 vehicles. It has about 260 thousand square meters of warehouse resources throughout the country. It can provide cold storage, refrigeration, and storage of dangerous goods.

\section{B. The basic practice of RK logistics customer relationship management}

The root cause of customer relationship management is the pursuit of profit and the product of the development of the times. In order to retain old customers and attract new customers, an enterprise must change its former thinking. Have to change from the seller's market to the buyer's market, customer centric, starting from the needs of customers, meet customer needs first, and then continuously improve service quality. Make customers feel satisfied, thereby creating loyalty and bringing potential customers to the enterprise. In the final analysis, customer requirements, IT technology and management concepts promote the emergence of customer relationship management. RK logistics in the implementation of customer relationship management, each customer's services, requirements and responsibility departments and other provisions, and as a staff code of conduct.

- $\quad$ Person in charge is responsible for providing logistics one-stop service

- To subdivide customers and do the service of key accounts

- Occasional visits to key accounts

- Management of customer complaints

\section{APPLICATION OF CUSTOMER RESCUE MODEL IN RK LOGISTICS UNDER NEW RETAIL BACKGROUND}

New retail provides a wider range of experiential consumer services, consumer scene is the "new retail" the most important direction of development, but also the future direction of customer demand. At present, only a small number of shopping malls, restaurants, entertainment as one of the large entities, shopping centers in this area developed better. Online electricity providers and offline entities retail experience combined, and constantly strive to achieve consumer scenarios, is currently being discussed and practice of the main model. Customer churn is a huge loss for businesses in the new retail context. However, a rational analysis is needed to save customers. If the cost is higher than the value of the customer to save, even if successfully saved the customers, enterprises will not give up the loss outweighs the gain, customers, save the limited resources of the enterprise, to find new customers or better service to key customers [6]. Although there is no guarantee that the rescue will succeed, it is only after the implementation of the rescue that we can know whether it will succeed or not. Therefore, for the customer who needs to be 
rescued, it is necessary to do everything possible to save it within the scope of the cost savings.

\section{A. Overview of customer rescue models}

The paper argues the theory of customer churn mainly involves three aspects, such as identifying the types of customer churn, calculating surplus, lifetime value and saving costs, and making rescue plans, as shown in Fig. 1.

\section{1) Classification of lost customers}

Customer churn refers to the diversion of customers to other suppliers, or the absence of consumption of goods or services within the enterprise for a period of time.

In case of customer churn, we must first judge the type of customer churn, and then determine if it needs to be rescued.

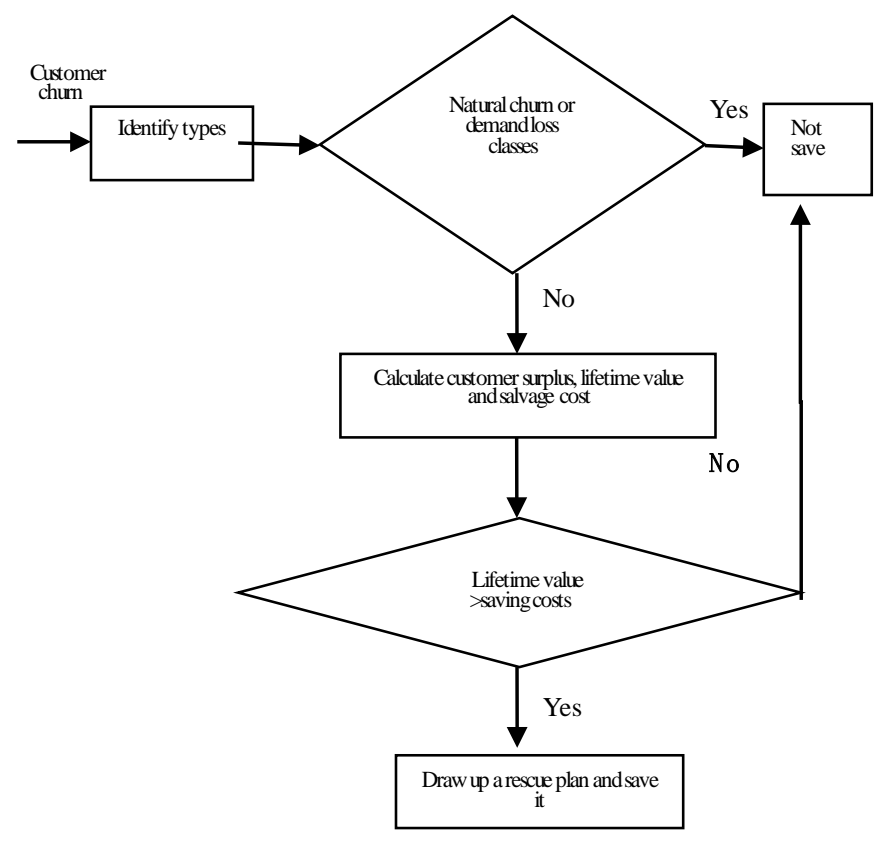

Fig. 1. Customer churn and customer rescue

Generally classified as:

(1) Natural wastage. Clients, immigrants, deaths, etc.

(2) Demand change class. That is, the customer's own needs have changed

(3) Loss of interest category. That is, customers turn to competitors because of price

(4) Disappointment and loss. That is, the customer is not satisfied with the goods or services of the enterprise and turns to competitors

Generally, because of their own reasons for the loss of customers accounted for relatively large. For the loss of customers caused by natural change and demand change, the rescue of enterprises is futile. Only the loss of interests and disappointment can be saved by enterprises. But the disappointment loss class is more important to the enterprise loyalty, so it is the key target that the enterprise saves.

\section{2) Determination of salvage costs}

The customer's value to the enterprise includes not only the direct profits of its own consumption, but also the indirect profits of introducing new customers. Save the customer churn fees include gift fees, communication fees, labor costs, save the cost limit criterion is customer lifetime value is less than the increase due to save, save the ultimate purpose of customers is to enable customers to rise in value. International customer lifetime value (CLV) is usually used to measure customer's value. CLV reflects the net present value of the customer's profits for the enterprise [7]. It is an important basis for determining the cost of the rescue.

\section{a) Computational Hypothesis}

A, there are only two behaviors for customers: no loss $\left(\right.$ probability $\left.^{\eta}\right)$, and loss (probability $(1-\eta)$ )

$\mathrm{B}$, in the first year, the customer was lost, the company was rescued in time. The cost of salvation for each lost customer was saved, and the rescue may be successful or unsuccessful.

C, only unsatisfied customers will complain to others and have a ripple effect.

$\mathrm{D}$, satisfaction ripple factor $r_{1}$ will increase the lifetime value of the customer. Loss sweep factor $\boldsymbol{r}_{2}$ will reduce customer lifetime value

\section{b) Symbolic description}

Narrow lifetime value: the cash flow generated by a customer during the entire period of maintaining a relationship with a company.

Net present value: the difference between the discounted value of the future cash flow generated by an investment and the cost of the project's investment.

Discount rate: the interest rate used to change future payments to the present value, or the holder seeks to honor the bank with an instrument not due for maturity, and the bank deducts interest on the current interest rate.

TABLE I. MODEL SYMBOL AND ITS SPECIFIC IMPLICATIONS

\begin{tabular}{|l|l|l|l|}
\hline Symbol & Explain & Symbol & Explain \\
\hline$V_{0}$ & $\begin{array}{l}\text { Narrow lifetime } \\
\text { value }\end{array}$ & $\theta$ & $\begin{array}{l}\text { Probability of } \\
\text { customer churn }\end{array}$ \\
\hline$V_{t}$ & $\begin{array}{l}\text { Net profit present to } \\
\text { customers after loss }\end{array}$ & $r_{1}$ & $\begin{array}{l}\text { Satisfactory sweep } \\
\text { coefficient }\end{array}$ \\
\hline$C$ & $\begin{array}{l}\text { The cost of salvage } \\
\text { is set as a constant }\end{array}$ & $r_{2}$ & $\begin{array}{l}\text { Loss sweep } \\
\text { coefficient }\end{array}$ \\
\hline$\eta$ & $\begin{array}{l}\text { The probability that } \\
\text { customers will not } \\
\text { run away }\end{array}$ & $\phi(t)$ & $\begin{array}{l}\text { Extent to which } \\
\text { customer lifetime } \\
\text { values are utilized }\end{array}$ \\
\hline$\lambda$ & $\begin{array}{l}\text { Probability of } \\
\text { salvage success }\end{array}$ & $i$ & Discount rate \\
\hline
\end{tabular}

c) Basic algorithm

If the probability of a client's successful rescue is set $\lambda$, then the probability of salvage failure is $(1-\lambda)$.

The first step is to calculate the expected value of the customer's lifetime value in the case of salvage $E(V)$

First, the customer lifetime value is calculated as a salvage success: 


$$
V_{1}=V_{0}-\frac{C}{(1+i)^{t+1}}
$$

When the salvage fails, the customer's lifetime value is:

$$
V_{2}=\left[V_{t}-\frac{C}{(1+i)^{t+1}}\right] \times(1+\theta)+\left[V_{t}-\frac{C}{(1+i)^{t+1}}-r_{2} V_{0}\right] \times \theta
$$

Finally, the mathematical expectation of the customer's lifetime value under the condition of saving is calculated:

$$
E_{(V)}=V_{1} \lambda+V_{2}(1-\lambda)
$$

The second step is to calculate the life value of the lost customer in the case of non-rescue:

$$
V_{n}=-\left(r_{2} \theta-\varphi_{(t)}\right) V_{0}
$$

The third step is to determine the upper limit of the cost of the rescue. It is necessary to save the customer's lifetime value, that is, to raise the value of the customer's lifetime. That is $E_{(V)}-V_{(n)}>0$. Considering the rescue after the success of one again with a loss, so $C<E_{(V)}-V_{(n)}$ the times safety coefficient, so the simplification, can save cost upper bound:

$$
C<\frac{1}{2}\left[\left(1-\varphi_{(t)}\right)+r_{2} \theta\right] \lambda V_{0}(1+i)^{t+1}
$$

That is, when the loss of customers $C$, the cost of the most expensive $C$, and if the cost is greater than, even if the successful rescue of the customer, the customer's lifetime value will be reduced, and bring negative profits to enterprises, there is no need to save.

\section{B. Taking the Fs project of RK logistics operation as an example, the algorithm of saving cost is determined}

RK logistics branch has business contacts with Fs since 2014 and customer relationship life cycle is 10 years. The actual business data for the last four years and the forecast data for 6 years from 2017 are shown below. The customer's future loyalty characteristics are as follows: The probability of high satisfaction without loss is $\eta=3 \%$, Satisfactory sweep coefficient $r_{1}=2$, In 2017, there may be a loss, and if the loss occurs, it is estimated that 50 thousand Yuan will be used to save the customer, The probability of salvage success is $\lambda=25 \%$, The probability of loss is not satisfied $\theta=3 \%$, Loss sweep coefficient $r_{2}=2$. Suppose the bank's discount rate remains unchanged at an annual rate of $10 \%$, that is $i=10 \%$

TABLE II. 2014-2017 BUSINESS DAT A ST ATISTICS AND 2018-2023 YEAR DATA FORECAST FORM

\begin{tabular}{|c|c|c|c|c|c|c|c|c|c|c|}
\hline Particular year & $\mathbf{2 0 1 4}$ & $\mathbf{2 0 1 5}$ & $\mathbf{2 0 1 6}$ & $\mathbf{2 0 1 7}$ & $\mathbf{2 0 1 8}$ & $\mathbf{2 0 1 9}$ & $\mathbf{2 0 2 0}$ & $\mathbf{2 0 2 1}$ & $\mathbf{2 0 2 2}$ & $\mathbf{2 0 2 3}$ \\
\hline $\begin{array}{c}\text { Gross profit on } \\
\text { account }\end{array}$ & 15.3 & 35.6 & 58 & 76.1 & 90 & 90 & 90 & 70 & 51 & 15 \\
\hline austomer cost & 6.1 & 4.3 & 4.5 & 5.6 & 5 & 5 & 6 & 15 & 9 & 1 \\
\hline Net profit & 9.2 & 31.3 & 53.5 & 70.5 & 85 & 85 & 84 & 55 & 42 & 14 \\
\hline
\end{tabular}

The data from the above and TABLE II shows that the starting point for the value calculation is 2014.
The customer's narrow lifetime value utilization is

$$
\phi(t)=\frac{V_{t}}{V_{0}}
$$

First, calculate the customer's narrow lifetime value:

$$
V_{0}=\frac{9.2}{1 \cdot 1^{1}}+\frac{31 \cdot 3}{1 \cdot 1^{2}}+\frac{53 \cdot 5}{1 \cdot 1^{3}}+\frac{70.5}{1 \cdot 1^{4}}+\frac{85}{1 \cdot 1^{5}}+\frac{85}{1 \cdot 1^{6}}+\frac{84}{1 \cdot 1^{7}}+\frac{55}{1 \cdot 1^{8}}+\frac{42}{1 \cdot 1^{9}}+\frac{14}{1 \cdot 1^{10}}=315 \cdot 31
$$
been:

By $2016(t=4)$, the net profit generated by the customer has

$$
V_{t}=\sum_{k=1}^{t} \frac{M_{k}}{(1+i)^{k}}=\frac{9.2}{1.1^{1}}+\frac{31 \cdot 3}{1 \cdot 1^{2}}+\frac{53.5}{1 \cdot 1^{3}}+\frac{70.5}{1.1^{4}}=122.58
$$

Therefore, the lifetime value utilization of the customer is

$$
\phi(t)=\frac{V_{t}}{V_{0}}=\frac{122.58}{315.31} * 100 \%=38.88 \%
$$

To be $t=4, \eta=3 \%, \lambda=25 \%, \theta=3 \%, i=10 \%, C=5$, $r_{1}=2, r_{2}=2$ and bring into (5) the maximum cost limit for:

$$
C<\frac{1}{2}[(1-38.88 \%)+2 * 3 \%] * 25 \% * 315.31 *(1+10 \%)^{4+1}=42.61
$$

The cost of saving the customer was $\$ 426$ thousand and 100 in 2017. If it is more than 426 thousand and 100 Yuan, there is no need to save it.

\section{LOGISTICS CUSTOMER RELATIONSHIP MANAGEMENT} MAINTENANCE STRATEGY UNDER NEW RETAIL BACKGROUND

\section{A. Implementing the management thought of "customer centered"}

First of all, the "customer centric" thinking into the enterprise culture, so that each enterprise employees are accepted and recognized the idea. Second, the need to implement the "customer centric" concept, which depends on the behavior of employees, employees are closely related to their daily work. For example, sincere treatment of customers, respect for customers, patience to deal with every urgent customer needs. The top management of an enterprise needs to set an example and act as a promoter [8]. They are the key factor in the implementation of "customer centric".

\section{B. Improve customer relationship management system}

The key indicators for the implementation of customer relationship management in third party logistics enterprises are customer value, customer segmentation, customer satisfaction and customer loyalty. Therefore, it is necessary to draw up a perfect system from customer records, customer service, customer visits, customer churn and customer data sharing. The key factor of successful implementation of customer relationship management can ensure the successful implementation of customer relationship management strategy in third party logistics enterprises. [9]

And effective information management system can guarantee the quality of customer service, enhance customer relations. For the third party logistics enterprises, a perfect information management system needs to link the enterprise, the customer and the carrier. Reduce the communication link, shorten the time of information sharing, and realize the accurate and accurate transfer of information between 
enterprises, so as to improve service quality and customer satisfaction. [10]

\section{Strengthen the maintenance of existing customers}

According to the existing data analysis, RK logistics management to maintain the relationship with existing customers, it is necessary to enhance the customer information management, improve the quality of service and the difference in three aspects: strengthening the service channel of increasing customer information management; enhance the differentiated service quality; increase the service channel.

\section{SUMMARY}

At present, customer relationship management is an important part of enterprise management, and has received widespread attention at home and abroad. However, the concept took the lead in the formation of foreign countries, the first to introduce the domestic customer relationship management system. Due to the different national conditions, the implementation of customer relationship management considerations is not the same, mechanically will produce some negative effects. Therefore, this paper first introduces the origin and development of customer relationship management, and at the same time describes some basic theories of customer relationship management. Including definition, function and value, according to first-hand information obtained during the internship of RK logistics customer service, analyze the current situation of RK logistics implementation of customer relationship management, find out the existing problems.

Secondly, taking Fs project as an example, we use the rescue model to compare the customer's surplus value and salvage cost to judge whether the customer is worth saving.

The maintenance of RK logistics customer relationship management suggestions: implement the "customer centric" management philosophy, improve customer relationship management system, the information system effectively and save the cost calculation of customers. In order to improve customer satisfaction and customer loyalty, improve the quality of logistics services and improve the level of logistics information.

\section{REFERENCE}

[1] Guang Xiaoli. Countermeasures of implementing customer relationship management in logistics enterprises [J]. Management staff, 2015 (26): 184. (In Chinese)

[2] Zhang Rui. Research on customer relationship management of third party logistics enterprises [D]. Beijing: Beijing Jiaotong University, 2014. (In Chinese)

[3] Fang Jie, Yang Lei. Fresh supply chain coordination under the background of new retail.[J]. Chinese circulation economy, 2017 (7) 10-16 (In Chinese)

[4] Zhao Shumei, Xu Xiaohong. Implications, models and development paths of new retailing [J]. China circulation economy, 2017 (5): 12-20. (In Chinese)

[5] Wang Yong; Deng Xudong. Empirical Study on performance evaluation of agricultural product supply chain based on factor analysis [J]. Chinese circulation economy, 2015 (3) 10-16. (In Chinese)

[6] Reinartz, Werner J. and V. Kumar. The Impact of Customer Relationship Characteristics on Pro fitable Lifetime Duration [J]. Journal of Marketing, 2003, 67(1):77-99.

[7] Ni Xiangyun, Liu Wei, Yuan Xin. Talking about the management of large customers in third party logistics [J]. Modern business, 2014 (33): 205-206. (In Chinese)

[8] Hu Lizeng, Xue Hengxin, Zhao Ziqiang. Based on customer lifetime value maximization as the criterion of customer churn model [J]. to save the vitality of enterprises, 2005, (9): 24 - 26 (In Chinese)

[9] Sun Chengzhi, Liu Weiqing. Research on customer relationship management of third party logistics enterprise [J]. Shopping mall modernization, 2011 (634): 63-64. (In Chinese)

[10] Liu Zengwu. Research on customer relationship management evaluation system of third party logistics [J]. East China economic management, 2010 (5): 119-122. (In Chinese) 